\title{
Representation of ISIS actions in Television Documentary: Integrating storytelling into Multimodal Discourse Analysis
}

\author{
${ }^{1}$ Ali Abdullah Saleh, ${ }^{2}$ Kawa Abdulkareem Rasul, ${ }^{3}$ Ken Fero \\ ${ }^{1} \mathrm{PhD}$ Student at Salahaddin University-Erbil Lecturer at Erbil Polytechnic University, ${ }^{2}$ Erbil Polytechnic University - \\ Iraq, ${ }^{3}$ Coventry University- United Kingdom
}

\begin{abstract}
Islamic State of Iraq and Syria ISIS rules in Iraq lasted three years, during its rule many new televisions have made reports to represent its actions, however only very view of them produced a documentary programme in detail that contains episodes. This paper shows 'ISIS were here' is a television documentary programme produced in 2017 by Rudaw Television a Kurdish Channel based in Kurdistan Region of Iraq, the programme broadcasted in Kurdish language, intensively and systematically represented the actions of ISIS by using visual aids. The results show that the programme conveys the destructive of the radical organization, and ISIS does not represent Islam through using Multimodal Discourse Analysis, and based on semiotic codes, meaning is realized through more than one semiotic code
\end{abstract}

Keywords:Documentary Programme, MDA, Myth, Semiotic Codes, Television, Rudaw. 